\title{
Neonatal brain oxygenation during thoracoscopic correction of esophageal atresia
}

\author{
Stefaan H. A. J. Tytgat ${ }^{1}$ Maud Y. A. van Herwaarden ${ }^{1}$ Lisanne J. Stolwijk $^{1,2}$ • \\ Kristin Keunen ${ }^{2} \cdot$ Manon J. N. L. Benders $^{2} \cdot$ Jurgen C. de Graaff $^{3}$ • \\ Dan M. J. Milstein ${ }^{4}$ - David C. van der Zee ${ }^{1} \cdot$ Petra M. A. Lemmers $^{2}$
}

Received: 12 June 2015/Accepted: 4 September 2015/Published online: 21 October 2015

(C) The Author(s) 2015. This article is published with open access at Springerlink.com

\begin{abstract}
Background Little is known about the effects of carbon dioxide $\left(\mathrm{CO}_{2}\right)$ insufflation on cerebral oxygenation during thoracoscopy in neonates. Near-infrared spectroscopy can measure perioperative brain oxygenation [regional cerebral oxygen saturation $\left.\left(\mathrm{rScO}_{2}\right)\right]$.

Aims To evaluate the effects of $\mathrm{CO}_{2}$ insufflation on $\mathrm{rScO}_{2}$ during thoracoscopic esophageal atresia (EA) repair.

Methods This is an observational study during thoracoscopic EA repair with $5 \mathrm{mmHg} \mathrm{CO}_{2}$ insufflation pressure. Mean arterial blood pressure (MABP), arterial oxygen saturation $\left(\mathrm{SaO}_{2}\right)$, partial pressure of arterial carbon dioxide $\left(\mathrm{paCO}_{2}\right), \mathrm{pH}$, and $\mathrm{rScO}_{2}$ were monitored in 15 neonates at seven time points: baseline (T0), after anesthesia induction (T1), after $\mathrm{CO}_{2}$-insufflation (T2), before $\mathrm{CO}_{2}$ exsufflation (T3), and postoperatively at 6 (T4), 12 (T5), and $24 \mathrm{~h}$ (T6).

Results MABP remained stable. $\mathrm{SaO}_{2}$ decreased from $\mathrm{T} 0$ to $\mathrm{T} 2[97 \pm 3-90 \pm 6 \%(p<0.01)] . \mathrm{PaCO}_{2}$ increased
\end{abstract}

Stefaan H. A. J. Tytgat

s.tytgat@umcutrecht.nl

1 Department of Pediatric Surgery, Wilhelmina Children's Hospital, University Medical Center Utrecht, KE 04.140.5, P.O. Box 85090, 3508 AB Utrecht, The Netherlands

2 Department of Neonatology, Wilhelmina Children's Hospital, University Medical Center Utrecht, KE 04.123.1, P.O. Box 85090, 3508 AB Utrecht, The Netherlands

3 Department of Anesthesiology, Wilhelmina Children's Hospital, University Medical Center Utrecht, KE 04.123.1, P.O. Box 85090, 3508 AB Utrecht, The Netherlands

4 Department of Oral and Maxillofacial Surgery, Academic Medical Center, Meibergdreef 9, 1105 AZ Amsterdam, The Netherlands from T0 to T2 $[41 \pm 6-54 \pm 15 \mathrm{mmHg}(p<0.01)] . \mathrm{pH}$ decreased from $\mathrm{T} 0$ to $\mathrm{T} 2$ [7.33 $\pm 0.04-7.25 \pm 0.11$ $(p<0.05)]$. All parameters recovered during the surgical course. Mean $\mathrm{rScO}_{2}$ was significantly higher at $\mathrm{T} 1$ compared to T2 $[77 \pm 10-73 \pm 7 \%(p<0.05)]$. Mean $\mathrm{rScO}_{2}$ levels never dropped below a safety threshold of $55 \%$.

Conclusion The impact of neonatal thoracoscopic repair of EA with insufflation of $\mathrm{CO}_{2}$ at $5 \mathrm{mmHg}$ was studied. Intrathoracic $\mathrm{CO}_{2}$ insufflation caused a reversible decrease in $\mathrm{SaO}_{2}$ and $\mathrm{pH}$ and an increase in $\mathrm{paCO}_{2}$. The $\mathrm{rScO}_{2}$ was higher at anesthesia induction but remained stable and within normal limits during and after the $\mathrm{CO}_{2}$ pneumothorax, which suggest no hampering of cerebral oxygenation by the thoracoscopic intervention. Future studies will focus on the long-term effects of this surgery on the developing brain.

Keywords Cerebral oxygenation - Esophageal atresia · Neonate · Thoracoscopy · Near-infrared spectroscopy

$\begin{array}{ll}\text { Abbreviations } \\ \mathrm{CO}_{2} & \text { Carbon dioxide } \\ \mathrm{EA} & \text { Esophageal atresia } \\ \mathrm{FiO}_{2} & \text { Fraction of inspired oxygen } \\ \mathrm{Hb} & \text { Hemoglobin } \\ \mathrm{MABP} & \text { Mean arterial blood pressure } \\ \mathrm{NICU} & \text { Neonatal intensive care unit } \\ \mathrm{NIRS} & \text { Near-infrared spectroscopy } \\ \text { paCO } & \text { Partial pressure of arterial carbon dioxide } \\ \mathrm{Pmax} & \text { Maximum inspiratory pressure } \\ \mathrm{PT} & \text { Pneumothorax } \\ \mathrm{rScO} & \text { Regional cerebral oxygen saturation } \\ \mathrm{SaO}_{2} & \text { Arterial oxygen saturation } \\ \mathrm{tcNIRS}^{2} & \text { Transcranial near-infrared spectroscopy } \\ \mathrm{TEF} & \text { Tracheoesophageal fistula }\end{array}$


Congenital esophageal atresia (EA) with tracheoesophageal fistula (TEF) is principally corrected in the neonatal phase. Increasingly, the correction of atresia and closing of the fistula is performed via a thoracoscopic approach [1]. A low-pressure carbon dioxide $\left(\mathrm{CO}_{2}\right)$ pneumothorax (PT) environment collapses the right lung enough to visualize the atresic esophagus and TEF. The procedure is performed under permissive hypercapnic conditions [2, 3]. Recent literature addressing thoracoscopic procedures in neonates has specified some concerns regarding the extra $\mathrm{CO}_{2}$ load of applied PT with decreased venous return under elevated intrathoracic pressure. This may be hazardous to neonatal physiology [4] and the developing central nervous system. In particular, impairment of cerebral oxygenation levels in neonates undergoing thoracoscopic procedures has been reported [5].

During surgical procedures and at the patient bedside, neonatal brain hemodynamics and oxygenation can be assessed by transcranial near-infrared spectroscopy (tcNIRS). This tcNIRS permits continuous noninvasive monitoring over extended periods of time. Until now tcNIRS monitoring was not a standard procedure in most neonatal intensive care units (NICU)'s and in OR's during surgery of newborns. However, in recent years more information has become available concerning the relationship between low cerebral oxygenation monitored by NIRS and the occurrence of brain damage among newborns and young children [6-8]. Currently NIRS monitoring is routinely performed in our NICU and in our OR during thoracoscopic correction of EA. Thus far NIRS findings during thoracoscopic correction of EA of only two patients have been reported [5]. The aim of the present study was to investigate tcNIRS in the perioperative period of neonates elected for minimally invasive EA reconstruction.

\section{Methods}

Guidelines and procedures for this investigation were reviewed and approved by the institutional Medical Ethics Committee of the University Medical Center Utrecht. Parents were informed about the study design and procedures, and informed parental consent was obtained from both parents of each participating neonate. This study was performed in compliance with the principles established in the Helsinki Declaration (version Fortaleza, October 19, 2013). NIRS monitoring is already used as a standard clinical monitoring tool in the NICU of the Wilhelmina Children's Hospital.

\section{Patients}

In this single-center prospective observational study, 15 patients diagnosed with EA with TEF (Type C atresia), admitted to the NICU of the Wilhelmina Children's Hospital of the University Medical Center Utrecht were enrolled between January 2012 and September 2014. Preoperative workup consisted of screening for associated anomalies (VACTERL) including ultrasound of the heart and aorta to exclude right descending aortic involvement. Before surgery arterial and venous lines were placed for monitoring blood pressure, arterial blood sampling, and venous access, respectively. A suction drain was placed in the proximal esophageal pouch to prevent aspiration.

\section{Anesthesia}

All patients were subjected to a standardized anesthesia protocol. For the induction of anesthesia sevoflurane (6-8\% inspired concentration) was used with a 40-100\% fraction of inspired oxygen $\left(\mathrm{FiO}_{2}\right)$. After muscle relaxation with atracurium $(0.5 \mathrm{mg} / \mathrm{kg})$, the infants were tracheally intubated. Thoracoscopy was performed with both lungs ventilated. Anesthesia was maintained with sufentanil and an oxygen/air mixture and sevoflurane. During the procedure tcNIRS values and simultaneously monitored heart rate, blood pressure, arterial oxygen saturation $\left(\mathrm{SaO}_{2}\right)$, and end tidal $\mathrm{CO}_{2}$ values were collected and stored in a high frequency rate $(0.5 \mathrm{~Hz})$ on a PC (Bedbase software, UMC Utrecht, NL). Every 30 min blood samples (blood gas; Hb) were taken as part of the routine clinical procedure during thoracoscopic neonatal surgery. The aim was to establish stable anesthetic conditions based on the $\mathrm{rScO}_{2}, \mathrm{SaO}_{2}$ values, end tidal $\mathrm{CO}_{2}$ values and blood gas analysis by adjustment of respiratory settings in frequency, maximum inspiratory pressure (Pmax) and $\mathrm{FiO}_{2}$. Hypotension was prevented with fluid expansion or inotropes. The $\mathrm{CO}_{2}$ gas insufflation was temporarily stopped if the applied PT caused insufficient ability to adequately ventilate the patient.

\section{Surgery}

All surgery was performed in the same operating theater with a stable room temperature of $22 \pm 1{ }^{\circ} \mathrm{C}$. In one patient rigid bronchoscopy was performed prior to surgery to assess possible concomitant tracheomalacia and to locate the TEF. The patients were placed in a left laterally recumbent position on a heated operating table $\left(36 \pm 1{ }^{\circ} \mathrm{C}\right)$ and tilted $10^{\circ}-20^{\circ}$ reverse Trendelenburg. All thoracoscopic EA repairs were performed through the right thoracic cavity according to earlier described techniques [9]. In short, the PT was created through a 5-mm intercostal camera-trocar placed via an open incisional procedure. An intrathoracic pressure of $5 \mathrm{mmHg}$ was achieved with a flow of $1 \mathrm{~L} / \mathrm{min}$ insufflation with $\mathrm{CO}_{2}$. Two trocars were placed through two 3-mm 
wounds (one caudodorsal and one cranio-anterior from the camera-trocar). If necessary, an extra trocar was placed to manipulate the lung out of sight to maximize the operating field-of-view. The azygos vein was coagulated and transected when it blocked exposure of the TE junction; the TEF was subsequently ligated with a transfixing absorbable 4.0 Vicryl suture close to the trachea. After transection of the distal esophagus, the proximal pouch was opened. Finally, both ends of the esophagus were anastomosed with interrupted 5.0 absorbable Vicryl sutures over a nasogastric feeding tube.

\section{Regional cerebral oxygenation}

To measure $\mathrm{rScO}_{2}$, the INVOS 5100c near-infrared spectrometer (Covidien, Mansfield, Ma USA) was used. The NIRS-determined $\mathrm{rScO}_{2}$ was used as an estimator for changes in regional cerebral oxygenation. This measurement provides absolute values, is less sensitive to movement artifacts, and allows for comparison over time. The transducer, containing a light-emitting diode and two distant sensors (i.e., small adult sensor; SAFB-SM, Covidien), was carefully positioned and fixed gently to the frontoparietal surface of the infants head using an elastic band, at the NICU. Differential signals are obtained from these two sensors, and from these signals the $\mathrm{rScO}_{2}$ is calculated. The $\mathrm{rScO}_{2}$ measures the oxygen saturation of the brain tissue. In a mixture of venous (70-80\%), arterial, and capillary blood the oxygenated hemoglobin $(\mathrm{Hb}) /$ total $\mathrm{Hb}$ (oxygenated $\mathrm{Hb}+$ non-oxygenated $\mathrm{Hb}$ ) is calculated. Although it still cannot be used as a robust quantitative measurement of cerebral oxygenation, it can serve as a trend monitoring device to detect substantial changes in regional tissue oxygen saturation [10]. The $\mathrm{rScO}_{2}$ was monitored during the entire surgical procedure and continued after the patient had returned to the NICU. Detected $\mathrm{rScO}_{2}$ levels are considered within safe reference range in (preterm) neonates when values are between 55 and $85 \%$ [11-14]. When $\mathrm{rScO}_{2}$ values exceeded reference limits, anesthetic interventions were made according to our NICU protocol as described by Pellicer et al. and Naulaers et al. [15-17].

\section{Data acquisition}

Intraoperative hemodynamic parameters and data on $\mathrm{rScO}_{2}$, measured by NIRS (INVOS 4100-5100; Covidien, Mansfield, MA, USA), were continuously monitored and stored for offline analysis using locally developed software (BedBase/SignalBase; University Medical Center Utrecht, Utrecht The Netherlands). Data were analyzed during seven intervals that lasted $10 \mathrm{~min}$. These seven time points were as follows: baseline at the NICU ward (T0), directly after anesthesia induction (T1), 30 min after PT $\mathrm{CO}_{2}$-insufflation (T2), $30 \mathrm{~min}$ before PT $\mathrm{CO}_{2}$-exsufflation (T3), and postoperatively at 6 (T4), 12 (T5), and $24 \mathrm{~h}$ (T6).

\section{Statistical analysis}

Data analysis was performed using IBM SPSS statistics software package $\left(\right.$ IBM $^{\circledR}$ SPSS $^{\circledR}$ Statistics version 20, IBM Corp. Armonk, NY, USA). Data sets are presented as mean \pm SD or as median and range when indicated. The data at different time points was analyzed by related parametric or nonparametric methods as appropriate. When no differences were found in an overall analysis across all seven time points, for clinical reasons, analysis subsequently focused on differences between baseline, anesthesia induction and the initial phases of the surgical procedure. Differences between two time points were analyzed with a Student $t$ test. Differences between time points with a $p$ value $<0.05$ were considered statistically significant.

\section{Results}

Fifteen patients with type C EA (with distal TEF) had complete data registration and were eligible for analysis. Table 1 presents demographics and clinical characteristics of the patients in this study. Eight patients had associated comorbidities, of which two patients had a right descending aorta and two patients had non-cyanotic cardiac malformations that required surgical correction at a later stage; one patient with dextrocardia and partial anomalous pulmonary venous connection (PAPVC) and one patient with a malaligned ventricular septal defect with overriding aorta. All patients had an overall uneventful thoracoscopic correction of EA. Median time in the OR was 211 [126-387] min, and the median time of PT was 130 [74-260] $\mathrm{min}$.

\section{Intraoperative hemodynamic and cerebral oxygenation parameters}

Figure 1 summarizes selected perioperative hemodynamic and cerebral oxygenation parameters. All patients remained normothermic during surgery (data not shown). The applied $\mathrm{FiO}_{2}$ was $0.68 \pm 0.24$ at $\mathrm{T} 1$ (anesthesia induction), $0.59 \pm 0.17$ at $\mathrm{T} 2$ and $0.49 \pm 0.16$ at T3 (end of insufflation) $(p<0.05)$. Median inspiratory Pmax [range] was 21 [14-26] $\mathrm{cmH}_{2} \mathrm{O}$ at $\mathrm{T} 2$ and 20 [17-28] $\mathrm{cmH}_{2} \mathrm{O}$ at $\mathrm{T} 3$. Median respiratory frequency was 42 [30-90] at T2 and 40 [28-69] at T3. Changes in MABP were not significant and measurements remained within physiological range (Fig. 1A). Hypotension was prevented by fluid expansion 
Table 1 Patient characteristics of 15 patients that had a thoracoscopic correction of an esophageal atresia with tracheoesophageal fistula

\begin{tabular}{ll}
\hline Clinical characteristics & $N=15$ \\
Gender (M:F) & $10: 5$ \\
Gestational age (weeks) & $39[36-42]$ \\
Postnatal age at surgery (days) & $2[1-7]$ \\
Birth weight (grams) & $2962[2155-4490]$ \\
Apgar score & \\
After 1 min & $9[4-10]$ \\
After 5 min & $9[5-10]$ \\
Other comorbidity & Cor vitium stable hemodynamics 4 \\
No comorbidity $N=7$ & Cor vitium requiring later surgery 2 \\
One or more associated anomalies $N=8$ & Right descending aorta 2 \\
& Tracheomalacia 2 \\
& Duodenal atresia 1 \\
& Anal atresia 1 \\
Duration (min) & Vertebrae/rib deformity 5 \\
Time on OR & \\
Surgery & 211 [126-387] \\
Pneumothorax & 148 [83-274] \\
\hline
\end{tabular}

Data are presented as median [range] and administration of dopamine in a range of 1-20 $\mathrm{mcg} /$ $\mathrm{Kg} / \mathrm{min}$ in 10 of $15(66 \%)$ patients at T2 and to 12 of 15 $(80 \%)$ patients at T3. A significant decrease in $\mathrm{SaO}_{2}$ was observed at PT application. $\mathrm{SaO}_{2}$ decreased from $97 \pm 3 \%$ at T0 (baseline) to $90 \pm 6 \%$ at T2 (PT application) $(p<0.01) . \mathrm{SaO}_{2}$ recovered to normal ranges during the procedure (Fig. 1B). $\mathrm{PaCO}_{2}$ increased from $41 \pm 6 \mathrm{mmHg}$ at $\mathrm{T} 0$ to $54 \pm 15 \mathrm{mmHg}$ at $\mathrm{T} 2(p<0.01)$ and then recovered to normal ranges during the procedure (Fig. 1C). Arterial sampled $\mathrm{pH}$ decreased from $7.33 \pm 0.04$ at T0 to $7.25 \pm 0.11$ at T2 $(p<0.05)$. It then recovered to normal ranges during the procedure (Fig. 1D). Continuous monitoring of cerebral oxygenation was successful in all 15 neonates. Mean $\mathrm{rScO}_{2}$ was significantly higher at $\mathrm{T} 1$ compared to $\mathrm{T} 2 ; 77 \pm 10$ and $73 \pm 7 \%$ respectively $(p<0.05)$. In none of the neonates, the mean $\mathrm{rScO}_{2}$ dropped below the safety threshold of $55 \%$ during or after surgery (Fig. 1E).

\section{Discussion}

The aim of this study was to investigate the effects of the installation of $\mathrm{a} \mathrm{CO}_{2}$ PT on the hemodynamics and cerebral oxygenation of neonates receiving thoracoscopic correction of EA. We observed that surgery with an intrathoracic pressure of $5 \mathrm{mmHg}$ can be performed, while the MABP remains within normal limits. Application of the PT initially lowers $\mathrm{SaO}_{2}$, raises $\mathrm{paCO}_{2}$, and lowers arterial $\mathrm{pH}$ levels. These parameters were corrected through the course of surgery by changes in the ventilation. Under these conditions, cerebral saturation remained within the safety range during the whole procedure. Furthermore, in the postoperative phase cerebral oxygenation and all other monitored parameters remained within normal limits. Our results suggest that a thoracoscopic procedure with a $\mathrm{CO}_{2}$ PT set at a pressure of $5 \mathrm{mmHg}$ and flow of $1 \mathrm{~L} / \mathrm{min}$ can be performed under conditions that allow for reversible arterial blood gas disturbances, with cerebral NIRS values that are elevated during anesthesia induction but that remain stable during and after the PT application.

A large number of pediatric surgical indications can be successfully managed by minimally invasive techniques [18], especially for cases involving treatment of EA. In an increasing number of pediatric surgical centers, these atresias are managed by thoracoscopic interventions [19]. Although benefits of either open or thoracoscopic approach to EA surgery remain to be proven in randomized studies [20], the thoracoscopic approach favors advantages supportive of less postoperative pain, shorter hospital stay [21], less scoliosis caused by rib fusion, decreased respiratory impairment, and improved overall cosmetic result $[3,22,23]$.

Despite plausible clinical advantages favoring thoracoscopic EA surgery, concerns have been raised regarding the safety of these thoracoscopic interventions in neonates. These concerns focus mostly on the impact of the applied pressurized $\mathrm{CO}_{2} \mathrm{PT}$ on neonatal hemodynamics and organ perfusion [3, 4, 20, 24, 25]. Intrathoracic $\mathrm{CO}_{2}$ insufflation collapses the lung, which adversely affects the $\mathrm{O}_{2}$ and $\mathrm{CO}_{2}$ 
Fig. 1 A-E Perioperative physiological parameters and cerebral oxygenation data at baseline (T0), anesthesia induction (T1), $30 \mathrm{~min}$ after $\mathrm{CO}_{2}$ insufflation (T2), $30 \mathrm{~min}$ before ending $\mathrm{CO}_{2}$ insufflation (T3) and in the postoperative phase at 6 (T4), 12 (T5), and $24 \mathrm{~h}$ (T6). MABP mean arterial blood pressure (A), $\mathrm{SaO}_{2}$ saturation of peripheral oxygen (B), $\mathrm{paCO}_{2}$ partial pressure of arterial carbon dioxide $(\mathbf{C})$, arterial sampled $\mathrm{pH}(\mathbf{D}), \mathrm{rScO}_{2}$ regional cerebral oxygen saturation (E). Significant differences are marked asterisk and are presented in the figures with Student $t$ test $p$ values
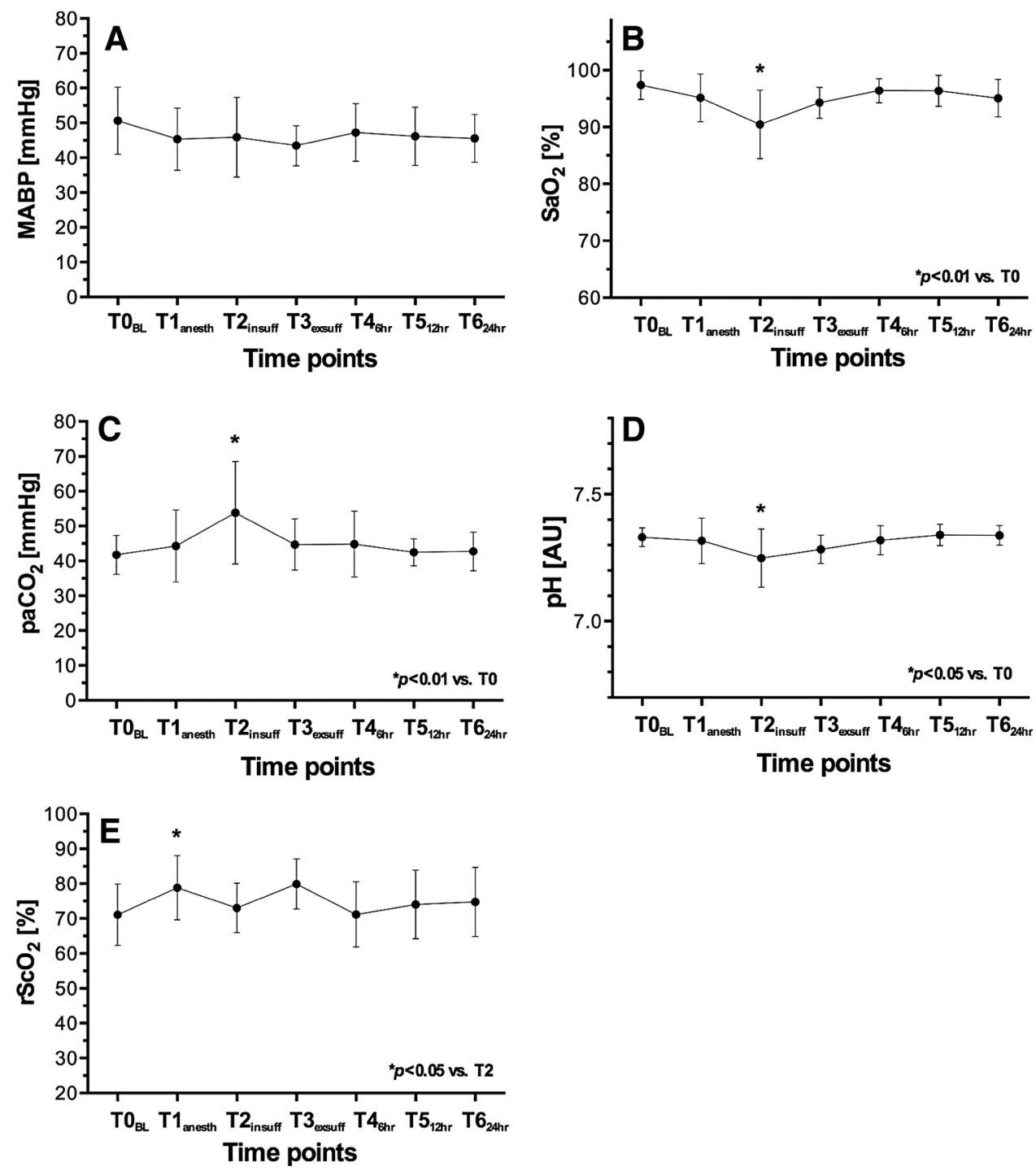

exchange causing hypoxia and hypercarbia. Another factor that causes hypercarbia is the excess systemic $\mathrm{CO}_{2}$ load that is absorbed from the thoracic cavity during the $\mathrm{PT} \mathrm{CO}_{2}$ gas insufflation [5]. Hypoxia and especially hypercarbia with a lowered $\mathrm{pH}$ cause vasodilatation of the cerebral vessels in the neonate [26-28]. When lower arterial oxygen saturation causes lower cerebral oxygen supply, the hypercarbia-induced vasodilatation can compensate for the reduced cerebral oxygen supply if blood pressure remains adequate. Diminished perioperative cerebral oxygen saturation during neonatal cardiothoracic surgery is correlated with poor neurodevelopment outcomes $[6,7]$ and brain magnetic resonance imaging abnormalities at 1 year [8]. Recently, Bishay et al. [5] reported that severe perioperative hypercarbia, acidosis, and decreased cerebral oxygenation were seen in neonates that underwent thoracoscopic surgery for EA and congenital diaphragmatic hernia. It is proclaimed that the reduction in the cerebral oxygenation lingered for up to $24 \mathrm{~h}$ postoperatively. However, in the paper by Bishay et al. [5] the $\mathrm{rScO}_{2}$ value at the start of operation of $87 \%$ was very high, possibly due to initial hyper-oxygenation. It decreased to $75 \%$ at the end of operation. Also in the postoperative phase, cerebral oxygenation levels remained within reference range.

Furthermore, in the published series on neonatal thoracoscopic interventions $[5,20]$ that describe the negative impact of $\mathrm{CO}_{2}$ application, PT pressures of up to $10 \mathrm{mmHg}$ were applied. A recent experimental study in piglets showed that $10 \mathrm{mmHg}$ PT pressures caused severe hemodynamic instability and decreased cerebral perfusion, whereas these conditions remained stable with PT pressures of $5 \mathrm{mmHg}$ [29]. The results from this piglet study suggest that the applied pressure of $5 \mathrm{mmHg}$, as used routinely in our clinic, has no severe adverse effects and seems safe to use in thoracoscopic procedures. 
In response to the concerns about thoracoscopic EA surgery, Conforti et al. [30] concluded that cerebral oxygenation remains stable during open EA correction. The results of our present study show that this conclusion is not exclusively reserved for open EA correction but that it is also possible during thoracoscopic surgery. We believe that close monitoring and a close collaboration between neonatologists, anesthesiologists, and pediatric surgeons is essential for achieving stable physiological conditions with sustained brain oxygenation levels. According to the anesthesia protocol, fluid expansion and inotropes were applied to prevent blood pressure from declining below physiological limits during the thoracoscopic procedure. Moreover, in the present study we observed that in the initial phase of surgery, installation of the PT caused arterial saturation to drop. To allow adequate ventilation, $\mathrm{CO}_{2}$ PT insufflation was then stopped until the patient had recovered. If reinstallation of $\mathrm{CO}_{2} \mathrm{PT}$ persisted in causing low oxygen saturation, insufflation pressures were not increased but an additional trocar was introduced to gently move the lung away from the operating field-of-view. Initial hypercarbia and consequent acidosis was alleviated during the operation by continuous adjustment of ventilator settings. Acceptable limits of perioperative $\mathrm{CO}_{2}$ blood gas values are as yet not known $[2,31]$. However, to ascertain $\mathrm{CO}_{2}$ and $\mathrm{pH}$ levels stayed within acceptable range, adequacy of ventilation is confirmed by arterial blood gas analysis at 30-min intervals [20, 30].

Whether the initial hypercapnia, which can have strong vasoactive effects [2, 26-28] and the acidosis, recorded in our study, could be detrimental for the developing neonatal brain is unknown [31, 32]. These blood gas results are comparable though to those seen during open EA surgery. In our study the initial $\mathrm{paCO}_{2}$ during the pneumothorax was $54 \mathrm{mmHg}$. It was $56 \mathrm{mmHg}$ in a series of patients that were operated via (open) thoracotomy in the study by Bishay et al. [20]. Also, the resulting acidosis in our series with a $\mathrm{pH}$ of 7.25 is comparable to a $\mathrm{pH}$ of 7.26 in the study of Bishay et al. [20]. In our study, cerebral oxygenation remained stable and not jeopardized during or after the thoracoscopic procedure. The initial increased cerebral NIRS values prior to the surgical procedure are also described in other studies of open or thoracoscopic neonatal surgery $[5,30]$. This could be a consequence of an increased supply of oxygen at the phase of anesthesia induction. Also in our study the highest median $\mathrm{FiO}_{2}$ was recorded at this time $(0.68 \pm 0.24)$.

In conclusion, thoracoscopic EA repair can be performed without the need for conversion or extended procedural times with $\mathrm{CO}_{2}$-insufflation pressures that are sustained around $5 \mathrm{mmHg}$. Cerebral oxygenation was stable within the normal range during and after the procedure. Close perioperative monitoring of neonatal brain oxygenation and close collaboration between surgeons, anesthesiologists and neonatologists will remain part of our operative protocol for patients undergoing thoracoscopic reconstruction of EA. Future studies in our institution will focus on the long-term effects of these types of surgery in neonates and the aim of understanding and avoiding impact on the neonatal brain with adverse neurodevelopmental outcomes.

Acknowledgments We gratefully acknowledge and thank all the families who kindly consented for participation in this investigation. We also thank the anesthesiologists, the operating theater staff and the NICU staff and nurses for their cooperation and support during this investigation.

\section{Compliance with ethical standards}

Disclosures The authors S.H.A.J. Tytgat, M.Y.A. van Herwaarden, L.J. Stolwijk, K. Keunen, M.J.N.L. Benders, J.C. de Graaff, D.M.J. Milstein, D.C. van der Zee and P.M.A. Lemmers have no financial ties or conflicts of interest to disclose.

Open Access This article is distributed under the terms of the Creative Commons Attribution 4.0 International License (http://crea tivecommons.org/licenses/by/4.0/), which permits unrestricted use, distribution, and reproduction in any medium, provided you give appropriate credit to the original author(s) and the source, provide a link to the Creative Commons license, and indicate if changes were made.

\section{References}

1. van der Zee DC, Tytgat SH, Zwaveling S, van Herwaarden MY, Vieira-Travassos D (2012) Learning curve of thoracoscopic repair of esophageal atresia. World J Surg 36:2093-2097

2. Mukhtar AM, Obayah GM, Elmasry A, Dessouky NM (2008) The therapeutic potential of intraoperative hypercapnia during video-assisted thoracoscopy in pediatric patients. Anesth Analg 106:84-88

3. Szavay PO, Zundel S, Blumenstock G, Kirschner HJ, Luithle T, Girisch M, Luenig H, Fuchs J (2011) Perioperative outcome of patients with esophageal atresia and tracheo-esophageal fistula undergoing open versus thoracoscopic surgery. J Laparoendosc Adv Surg Tech A 21:439-443

4. Laberge JM, Blair GK (2013) Thoracotomy for repair of esophageal atresia: not as bad as they want you to think! Dis Esophagus 26:365-371

5. Bishay M, Giacomello L, Retrosi G, Thyoka M, Nah SA, McHoney M, De Coppi P, Brierley J, Scuplak S, Kiely EM, Curry JI, Drake DP, Cross KM, Eaton S, Pierro A (2011) Decreased cerebral oxygen saturation during thoracoscopic repair of congenital diaphragmatic hernia and esophageal atresia in infants. J Pediatr Surg 46:47-51

6. Toet MC, Flinterman A, Laar I, Vries JW, Bennink GB, Uiterwaal CS, F Bel (2005) Cerebral oxygen saturation and electrical brain activity before, during, and up to 36 hours after arterial switch procedure in neonates without pre-existing brain damage: its relationship to neurodevelopmental outcome. Exp Brain Res 165:343-350

7. Hoffman GM, Brosig CL, Mussatto KA, Tweddell JS, Ghanayem NS (2013) Perioperative cerebral oxygen saturation in neonates with hypoplastic left heart syndrome and childhood neurodevelopmental outcome. J Thorac Cardiovasc Surg 146:1153-1164 
8. Kussman BD, Wypij D, Laussen PC, Soul JS, Bellinger DC, DiNardo JA, Robertson R, Pigula FA, Jonas RA, Newburger JW (2010) Relationship of intraoperative cerebral oxygen saturation to neurodevelopmental outcome and brain magnetic resonance imaging at 1 year of age in infants undergoing biventricular repair. Circulation 122:245-254

9. van der Zee DC, Bax NM (2003) Thoracoscopic repair of esophageal atresia with distal fistula. Surg Endosc 17:1065-1067

10. van Bel F, Lemmers P, Naulaers G (2008) Monitoring neonatal regional cerebral oxygen saturation in clinical practice: value and pitfalls. Neonatology 94:237-244

11. Kurth CD, Levy WJ, McCann J (2002) Near-infrared spectroscopy cerebral oxygen saturation thresholds for hypoxia-ischemia in piglets. J Cereb Blood Flow Metab 22:335-341

12. Dent CL, Spaeth JP, Jones BV, Schwartz SM, Glauser TA, Hallinan B, Pearl JM, Khoury PR, Kurth CD (2005) Brain magnetic resonance imaging abnormalities after the Norwood procedure using regional cerebral perfusion. $\mathrm{J}$ Thorac Cardiovasc Surg 130:1523-1530

13. Hou X, Ding H, Teng Y, Zhou C, Tang X, Li S, Ding H (2007) Research on the relationship between brain anoxia at different regional oxygen saturations and brain damage using near-infrared spectroscopy. Physiol Meas 28:1251-1265

14. Hyttel-Sorensen S, Pellicer A, Alderliesten T, Austin T, van Bel F, Benders M, Claris O, Dempsey E, Franz AR, Fumagalli M, Gluud C, Grevstad B, Hagmann C, Lemmers P, van Oeveren W, Pichler G, Plomgaard AM, Riera J, Sanchez L, Winkel P, Wolf M, Greisen G (2015) Cerebral near infrared spectroscopy oximetry in extremely preterm infants: phase II randomised clinical trial. BMJ 350:g7635

15. Pellicer A, Greisen G, Benders M, Claris O, Dempsey E, Fumagalli M, Gluud C, Hagmann C, Hellström-Westas L, HyttelSorensen S, Lemmers P, Naulaers G, Pichler G, Roll C, van Bel F, van Oeveren W, Skoog M, Wolf M, Austin T (2013) The SafeBoosC phase II randomised clinical trial: a treatment guideline for targeted near-infrared-derived cerebral tissue oxygenation versus standard treatment in extremely preterm infants. Neonatology 104:171-178

16. Naulaers G, Meyns B, Miserez M, Leunens V, Van Huffel S, Casaer P, Weindling M, Devlieger H (2007) Use of tissue oxygenation index and fractional tissue oxygen extraction as noninvasive parameters for cerebral oxygenation. A validation study in piglets. Neonatology 92:120-126

17. Naulaers G, Morren G, Van Huffel S, Casaer P, Devlieger H (2003) Measurement of tissue oxygenation index during the first three days in premature born infants. Adv Exp Med Biol 510:379-383

18. te Velde EA, Bax NM, Tytgat SH, de Jong JR, Travassos DV, Kramer WL, van der Zee DC (2008) Minimally invasive pediatric surgery: increasing implementation in daily practice and resident's training. Surg Endosc 22:163-166

19. Lal D, Miyano G, Juang D, Sharp NE, St Peter SD (2013) Current patterns of practice and technique in the repair of esophageal atresia and tracheoesophageal fistua: an IPEG survey. $\mathrm{J}$ Laparoendosc Adv Surg Tech A 23:635-638

20. Bishay M, Giacomello L, Retrosi G, Thyoka M, Garriboli M, Brierley J, Harding L, Scuplak S, Cross KM, Curry JI, Kiely EM, De Coppi P, Eaton S, Pierro A (2013) Hypercapnia and acidosis during open and thoracoscopic repair of congenital diaphragmatic hernia and esophageal atresia: results of a pilot randomized controlled trial. Ann Surg 258:895-900

21. Allal H, Pérez-Bertólez S, Maillet O, Forgues D, Doan Q, Chiapinelli A, Kong V (2009) Comparative study of thoracoscopy versus thoracotomy in esophageal atresia. Cir Pediatr 22:177-180

22. Rothenberg SS (2009) Experience with thoracoscopic tracheal surgery in infants and children. J Laparoendosc Adv Surg Tech A 19:671-674

23. Koga H, Yamoto M, Okazaki T, Okawada M, Doi T, Miyano G, Fukumoto K, Lane GJ, Urushihara N, Yamataka A (2014) Factors affecting postoperative respiratory tract function in type-C esophageal atresia. Thoracoscopic versus open repair. Pediatr Surg Int 30:1273-1277

24. Metzelder ML, Ure BM (2010) Minimally invasive pediatric surgery. Chirurg 81:71-80

25. Kalfa N, Allal H, Raux O, Lopez M, Forgues D, Guibal MP, Picaud JC, Galifer RB (2005) Tolerance of laparoscopy and thoracoscopy in neonates. Pediatrics 116:e785-e791

26. van Bel F, van de Bor M, Baan J, Ruys JH (1988) The influence of abnormal blood gases on cerebral blood flow velocity in the preterm newborn. Neuropediatrics 19:27-32

27. Tytgat SH, van der Zee DC, Ince C, Milstein DM (2013) Carbon dioxide gas pneumoperitoneum induces minimal microcirculatory changes in neonates during laparoscopic pyloromyotomy. Surg Endosc 27:3465-3473

28. Vanderhaegen J, Naulaers G, Vanhole C, De Smet D, Van Huffel S, Vanhaesebrouck S, Devlieger H (2009) The effect of changes in $\mathrm{PCO} 2$ on the fractional tissue oxygen extraction-as measured by near-infrared spectroscopy -in neonates during the first days of life. Eur J Paediatr Neurol 13:128-134

29. Stolwijk LJ, Tytgat SH, Keunen K, Suksamanapan N, van Herwaarden MY, Groenendaal F, Lemmers PM, van der Zee DC (2015) The effects of $\mathrm{CO}_{2}$-insufflation with 5 and $10 \mathrm{mmHg}$ during thoracoscopy on cerebral oxygenation and hemodynamics in piglets: an animal experimental study. Surg Endosc 29(9): 2781-2788

30. Conforti A, Giliberti P, Mondi V, Valfré L, Sgro S, Picardo S, Bagolan P, Dotta A (2014) Near infrared spectroscopy: experience on esophageal atresia infants. J Pediatr Surg 49:1064-1068

31. Bliss D, Matar M, Krishnaswami S (2009) Should intraoperative hypercapnia or hypercarbia raise concern in neonates undergoing thoracoscopic repair of diaphragmatic hernia of Bochdalek? J Laparoendosc Adv Surg Tech A 19(Suppl 1):S55-S58

32. Pierro A (2015) Hypercapnia and acidosis during the thoracoscopic repair of oesophageal atresia and congenital diaphragmatic hernia. J Pediatr Surg 50:247-249 